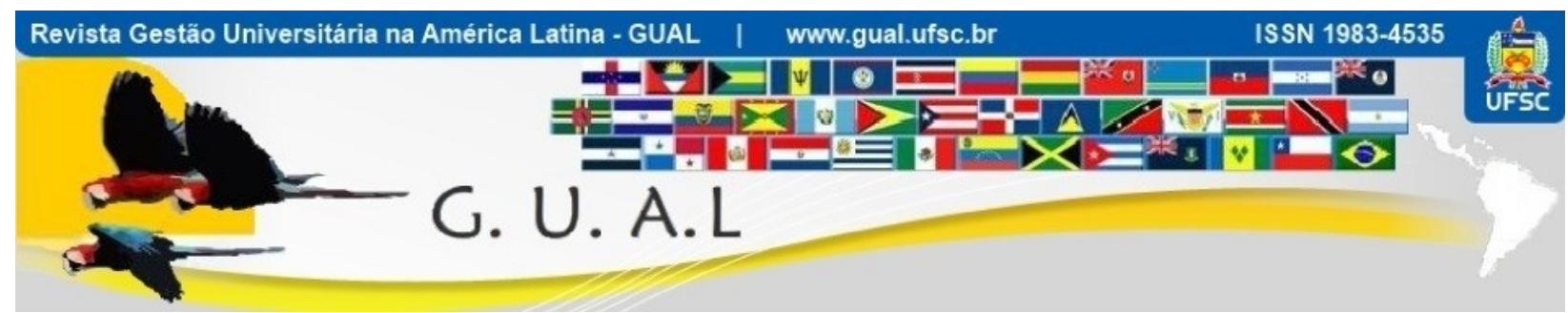

DOI: https://doi.org/10.5007/1983-4535.2021.e73094

\title{
A EXPRESSÃO DA LIDERANÇA NA PRÁTICA DOCENTE: UM ESTUDO COM PROFESSORES UNIVERSITÁRIOS DE CURSOS DE ADMINISTRAÇÃO
}

\section{THE EXPRESSION OF LEADERSHIP IN TEACHING PRACTICE: A STUDY OF UNIVERSITY PROFESSORS IN ADMINISTRATION COURSES}

\author{
Gustavo Lima Soares, Mestre \\ https://orcid.org/0000-0001-9143-0652 \\ glimasoares@gmail.com \\ Universidade do Vale do Itajaí | Escola de Negócios \\ Florianópolis | Santa Catarina | Brasil
}

Simone Ghisi Feuerschütte, Doutora

https://orcid.org/0000-0002-0963-1242 ghisi.simone@gmail.com

Universidade do Estado de Santa Catarina | Programa de Pós-Graduação em Administração Florianópolis | Santa Catarina | Brasil

Recebido em 19/abril/2020

Aprovado em 13/outubro/2020

Publicado em 01/janeiro/2021

Sistema de Avaliação: Double Blind Review

Esta obra está sob uma Licença Creative Commons Atribuição-Uso. 


\title{
RESUMO
}

A sala de aula e estratégias de ensino-aprendizagem têm sido debatidos como forma de explorar a importância dos processos de educação na construção da realidade. Assim, este artigo objetiva verificar a relação entre a percepção de prática docente de professores de cursos superiores de Administração e as concepções de liderança expressas em sala de aula. Com abordagem qualitativa, entrevistou-se quatorze professores de Universidades de Santa Catarina. Os resultados demonstraram as expressões de liderança nas práticas docentes de cada docente, quando consideradas suas dimensões: universidade, aluno, regulação, professor e processo educativo. Em geral, os professores consideram a universidade local ideal para educação, seus alunos precisam ser sujeitos dos processos de ensino e a lei tem impacto positivo em suas práticas. Os docentes consideram que seus papéis sejam de transmissores dos conteúdos e autoridades em sala; assim escolhem a aula expositiva e dialogada como estratégia. Quando relacionada 'prática docente' com as abordagens da liderança concluiu-se que, embora expressem liderança em suas práticas, não é possível delimitar seus comportamentos a uma única concepção de liderança.

Palavras-chave: Liderança. Prática Docente. Professor Líder.

\begin{abstract}
The classroom and teaching-learning strategies have been debated in order to explore the importance of the educational processes in the construction of reality. Thus, this article aims to verify the relationship between the perception of teaching practice of professors in Higher Administration courses and the concepts of leadership expressed in the classroom environment. A qualitative approach was used to interview fourteen professors from the Universities of Santa Catarina. The results showed the expression of leadership in each professor's teaching practices, considering the following dimensions: University, Student, Regulation, Professor, and Educational Process. In general, professors believe the University is an ideal place for education, where students need to be subject to the teaching processes and the law has a positive impact on their practices. The professors consider themselves to be transmitters of knowledge and authorities in class; this way, dialogic expository classes are chosen as a strategy. Finally, when teaching practice was related to leadership approaches, it was concluded that, although professors express leadership in their practices, it is not possible to limit their behaviors to this single conception.
\end{abstract}

Keywords: Leadership. Teaching Practice. Teacher Leader. 


\section{INTRODUÇÃO}

Os processos de ensino e aprendizagem, bem como os horizontes de atuação em sala de aula, têm sido tema de debates que circundam a importância da educação na construção da realidade social. De um ponto de vista genérico, a Universidade, enquanto instituição, tem papel fundamental na edificação da sociedade. Entre suas principais responsabilidades estão as funções sociais de formar profissionais qualificados, produzir conhecimentos e potencialidades investigativas (D’ANTOLA, 1992).

Inseridos neste contexto estão os profissionais responsáveis pela efetivação do processo de construção social, os docentes. De maneira geral o docente, possuidor de conhecimentos acadêmicos específicos sobre sua área de atuação, deve desenvolver em seu local de trabalho as suas competências práticas, promovendo para si e para os outros também aquelas de natureza cognitiva, afetiva e técnicas (PERRENOUD, 2001). Além disso, é papel do docente contribuir para que a escola superior, possa ser o ambiente adequado para o desenvolvimento de um ensino crítico, criador e até mesmo contestador da realidade. Tem então o docente, o papel de traduzir sua atuação em um certo tipo de "compromisso filosófico", onde o primordial está centrado no ato de ensinar e de aprender (D’ANTOLA, 1992).

Nessa perspectiva, a Universidade passa a ser o espaço onde a prática docente pode ser capaz de produzir uma mudança de comportamentos ou condutas, pelo exercício baseado na capacidade de observar e absorver conhecimentos (FREIRE, 1992). Núñes (2001) afirma que a formação profissional do professor em âmbito universitário, uma vez centrada na prática, tem a intenção de desenvolver uma atitude de reflexão e crítica a respeito de sua própria atuação e de sua capacidade de interlocução com o meio.

O ambiente de aprendizagem - neste caso, a Universidade - pressupõe a conjugação de influências internas e externas inerentes ao ambiente da educação, de maneira que a natureza da abordagem do docente (a sua prática) e os estilos de aprendizagem escolhidos caracterizam as maneiras predominantes de aprender dos acadêmicos. Tal processo não descarta, contudo, o entendimento de que a maneira como se aprende está intimamente ligada à forma como se ensina; ou seja, a compreensão de que o docente - enquanto líder no contexto da sala de aula - tende a ser a interferência mais forte no processo de aprendizagem (KOLB; KOLB, 2009). 


\section{A EXPRESSÃO DA LIDERANÇA NA PRÁTICA DOCENTE: UM ESTUDO COM PROFESSORES \\ UNIVERSITÁRIOS DE CURSOS DE ADMINISTRAÇÃO \\ DOI: https://doi.org/10.5007/1983-4535.2021.e73094}

Casassus (2008) destaca que, por meio de sua prática docente, o profissional busca conseguir um equilíbrio entre o emocional e o racional, favorecendo os processos de ensino e promovendo um processo de construção da liderança no espaço da sala de aula. Pode-se dizer, então, que a liderança expressa pelos docentes no ambiente acadêmico refere-se ao conjunto de habilidades demonstradas pelos professores que continuam a exercer a função de ensinar, mas também tem sua influência percebida para além da escola (DANIELSON, 2006).

O processo de construção e formulação do conhecimento pressupõe vínculo e sujeição à prática pedagógica do professor, em específico à escolha das ferramentas utilizadas para promover o ambiente de aprendizado ativo do aluno. Tardif (2002) propõe que a prática do professor tem a intencionalidade de estimular a interação humana, colocando em evidência a necessidade de práticas pedagógicas que propiciem a autonomia dos sujeitos de forma significativa. Desta forma, Thoonen et al (2011) afirmam que a liderança, em seu sentido abrangente, possui papel significativo na mudança educacional, relegando este processo ao relacionamento em que se constrói entre as partes (professores e alunos). Ou seja, pressupõese que o professor somente seja considerado um "bom professor" se evidenciar sua prática sustentando-a na necessidade de ser um líder dentro e fora de sala de aula, e não somente de estar líder por conta de sua posição institucional (BÜHLER, 2010).

Danielson (2006) defende, a esse respeito, que a liderança expressa por docentes pode estar diretamente relacionada com competências que facilitem a aprendizagem de seus alunos e sejam capazes de influenciar práticas profissionais para além da sala de aula. Esta perspectiva de análise da liderança no exercício da docência, em especial no âmbito do ensino superior, parece ser ainda pouco trabalhada no que diz respeito à área da Administração.

Diante do exposto, este artigo busca verificar a relação entre a percepção de prática docente de professores de cursos superiores na área de administração da Grande Florianópolis e as concepções de liderança expressas no contexto do ambiente de sala de aula. E está organizado em 6 sessões: Introdução, Referencial Teórico, Procedimentos Metodológicos, Resultados da Pesquisa, Considerações Finais e, Referências.

\section{REFERENCIAL TEÓRICO}

\subsection{PRÁTICA DOCENTE}

"A educação pode ser considerada um processo de humanização" (PIMENTA; ANASTASIOU, 2014, p. 97) ou, de maneira igualmente alusiva, o processo pelo qual os 


\section{A EXPRESSÃO DA LIDERANÇA NA PRÁTICA DOCENTE: UM ESTUDO COM PROFESSORES \\ UNIVERSITÁRIOS DE CURSOS DE ADMINISTRAÇÃO \\ DOI: https://doi.org/10.5007/1983-4535.2021.e73094}

indivíduos em uma organização social ambicionam, historicamente, uma inserção no modelo social amplamente aceito e difundido. $\mathrm{O}$ trabalho docente pode ser compreendido como um conceito de máxima generalidade, por meio do qual compreende-se que seja possível abarcar uma vasta área de atividades e características, principalmente ao analisar a docência no ensino superior (AQUINO; PUENTES, 2011). Pérez Gómez (1998) afirma que a formação docente apresenta três perspectivas: a acadêmica, a técnica e a prática, ou seja, em outras palavras, o docente, por meio de sua atuação como pesquisador e produtor de conhecimento teria, de acordo com o autor, a capacidade de desenvolver uma prática efetiva com o intuito de conhecer e intervir na realidade por meio da participação de seus alunos, transformando-os em protagonistas do processo de ensino.

A educação contemporânea tem sua origem nos primórdios da humanidade, com a tradição do conhecimento verbalmente transmitido de geração para geração, e pode, então, ser classificada como um processo de humanização (PIMENTA; ANASTASIOU, 2014). Ou seja, a educação é considerada o processo pelo qual o indivíduo tem a possibilidade de se inserir na sociedade humana.

Com relação à educação estruturalmente regulamentada, por sua vez, seu início tem ponto de partida com o surgimento da propriedade privada da terra e da necessidade de uma educação formal para os proprietários da terra (ARANHA, 2000). A tarefa da educação é a de garantir que a sociedade consiga se apropriar do instrumental científico, técnico, tecnológico, de pensamento, político, social e econômico, de desenvolvimento cultural para que sejam capazes de pensar e gestar soluções (PIMENTA; ANASTASIOU, 2014).

Com o advento da educação estruturalmente regulamentada, os processos de ensino são estudados ao longo do tempo, segundo diferentes enfoques, estes, por sua vez, analisam as abordagens do processo de ensino, ou concepções educacionais, partindo de seus princípios, dos componentes necessários ao fenômeno educativo e de seus efeitos sobre a sociedade e o indivíduo, uma vez que a educação, formal ou informal, sempre circundou como uma das principais preocupações da sociedade, principalmente quando vista como instrumento de socialização (SANTOS, 2005). Partindo-se do pressuposto que a ação do professor (sua prática) acontece em situações planejadas de ensino-aprendizagem, diferentes posicionamentos pessoais deveriam significar diferentes formas de ver o mundo e as situações subjacentes ao modo e a forma como o docente reconhece seu entorno (aluno, conteúdo, instituição, etc.) e a maneira como se percebe enquanto docente (MIZUKAMI, 1986). 
As concepções educacionais, utilizadas por Mizukami (1986) para analisar o posicionamento dos professores frente ao ambiente de sala de aula, na tentativa de explicar a maneira como este percebe a sala de aula são divididas em cinco abordagens. Para a Mizukami (1986), as diferentes abordagens da educação (tradicional, comportamentalista, humanista, cognitivista e sociocultural), são demonstradas por meio de quatro categorias de análise, quais sejam: a escola, o aluno, o professor e o processo de ensino e aprendizagem. Vale, contudo, ressaltar que no Brasil, especificamente a legislação acerca dos cursos superiores não discute ativamente o papel do docente, e espera-se tão somente que tenham uma preparação compatível com o desafio de formar futuros profissionais e gestores. (PLUTARCO; GRADVOHL, 2010).

É nesse contexto que se torna relevante refletir sobre a prática do professor universitário, no sentido de tornar-se uma tarefa que deve contemplar não somente os requisitos legais e institucionais presentes em documentos oficiais (Plano de Desenvolvimento Institucional, Projeto Pedagógico Institucional e Diretrizes Curriculares Nacionais), suas concepções educacionais e as possíveis estratégias de ensino que utilizam, mas a maneira como o docente enxerga o processo de ensino de maneira global, e como se posiciona frente ao seus diversos e interdisciplinares desafios por meio de suas ações.

Por fim, tem-se a intenção de apresentar as dimensões consideradas fundamentais para a delimitação do conceito de prática docente apresentado neste trabalho. No Brasil, especificamente, a prática docente do professor universitário está determinada não apenas sob a formalidade e as regras da IES em que atua, manifestando-se em sua ação concreta (MIZUKAMI, 1986), explícita e observável em sala de aula. Nessa perspectiva, apresenta-se, na figura 1, as dimensões consideradas determinantes da prática docente e que serviram como referência para analisar as evidências empíricas e para alcançar o propósito do presente estudo. 
Figura 1 Dimensões da Prática Docente

\begin{tabular}{|c|c|c|c|c|c|}
\hline $\begin{array}{l}\text { DIMENSÕES } \\
\text { ABORDAGENS }\end{array}$ & $\begin{array}{l}1^{\text {a }} \text { DIMENSÃO: } \\
\text { UNIVERSIDADE }\end{array}$ & 2a DIMENSÃO: ALUNO & $\begin{array}{l}3^{\text {a }} \text { DIMENSÃ̃: } \\
\text { REGULAÇÃ̃O }\end{array}$ & $\begin{array}{l}\text { 4 DIMENSÃO: } \\
\text { PROFESSOR }\end{array}$ & 5a DIMENSÃO: PROCESSO EDUCATIVO \\
\hline TRADICIONAL & $\begin{array}{l}\text { Lugar ideal para a realização } \\
\text { da educação } \\
\text { Normas disciplinares rígidas. } \\
\text { Prepara os indivíduos para a } \\
\text { sociedade. }\end{array}$ & $\begin{array}{l}\text { É um ser "passivo" que deve } \\
\text { assimilar os conteúdos } \\
\text { transmitidos pelo professor. } \\
\text { Deve dominar o conteúdo } \\
\text { cultura universal transmitido } \\
\text { pela escola. }\end{array}$ & $\begin{array}{l}\text { PDI } \\
\text { PPI } \\
\text { DCN } \\
\text { PPC }\end{array}$ & $\begin{array}{l}\text { É o transmissor dos } \\
\text { conteúdos aos alunos. } \\
\text { Predomina como } \\
\text { autoridade. }\end{array}$ & $\begin{array}{l}\text { Os objetivos educacionais obedecem à sequência lógica dos } \\
\text { conteúdos. } \\
\text { Os Conteúdos são baseados em documentos legais, selecionados a } \\
\text { partir da cultura universal acumulada. } \\
\text { Predominam aulas expositivas, com exercícios de fixação, leituras } \\
\text { e cópia. }\end{array}$ \\
\hline COMPORTAMENTALISTA & $\begin{array}{l}\text { Agência educacional. Modelo } \\
\text { empresarial aplicado à escola. } \\
\text { Divisão entre A escola } \\
\text { planejamento (quem planeja) e } \\
\text { execução (quem executa). No } \\
\text { limite, a sociedade poderia } \\
\text { existir sem escola. Uso da } \\
\text { teleducação. Ensino à } \\
\text { distância. }\end{array}$ & $\begin{array}{l}\text { Elemento para quem o material } \\
\text { é preparado. O aluno eficiente e } \\
\text { produtivo é o que lida } \\
\text { "cientificamente" com os } \\
\text { problemas da realidade. }\end{array}$ & $\begin{array}{l}\text { PDI } \\
\text { PPI } \\
\text { DCN } \\
\text { PPC }\end{array}$ & $\begin{array}{l}\text { É o educador que } \\
\text { seleciona, organiza e } \\
\text { aplica um conjunto de } \\
\text { meios que garantam a } \\
\text { eficiência e eficácia do } \\
\text { ensino. }\end{array}$ & $\begin{array}{l}\text { Os objetivos educacionais são operacionalizados e categorizados a } \\
\text { partir de classificações: gerais (educacionais) e específicos } \\
\text { (instrucionais). Ênfase nos meios: recursos audiovisuais, instrução } \\
\text { programada, tecnologias de ensino, ensino individualizado } \\
\text { (módulos instrucionais), "máquinas de ensinar", computadores, } \\
\text { hardwares, softwares. Os comportamentos desejados serão } \\
\text { instalados e mantidos nos alunos por condicionantes e } \\
\text { reforçadores. }\end{array}$ \\
\hline HUMANISTA & $\begin{array}{l}\text { Escola proclamada para todos. } \\
\text { "Democrática". Afrouxamento } \\
\text { das normas disciplinares. Deve } \\
\text { oferecer condições ao } \\
\text { desenvolvimento e autonomia } \\
\text { do aluno. }\end{array}$ & $\begin{array}{l}\text { Um ser "ativo". } \\
\text { Centro do processo de ensino e } \\
\text { aprendizagem. } \\
\text { Aluno criativo, que "aprendeu a } \\
\text { aprender". } \\
\text { Aluno participativo. }\end{array}$ & $\begin{array}{l}\text { PDI } \\
\text { PPI } \\
\text { DCN } \\
\text { PPC }\end{array}$ & $\begin{array}{l}\text { É o facilitador } \\
\text { aprendizagem. }\end{array}$ & $\begin{array}{l}\text { Os objetivos educacionais obedecem ao desenvolvimento } \\
\text { psicológico do aluno. } \\
\text { Os conteúdos programáticos são selecionados a partir dos } \\
\text { interesses dos alunos. } \\
\text { "Não-diretividade". } \\
\text { A avaliação valoriza aspectos afetivos (atitudes) com ênfase na } \\
\text { autoavaliação. }\end{array}$ \\
\hline COGNITIVISTA & 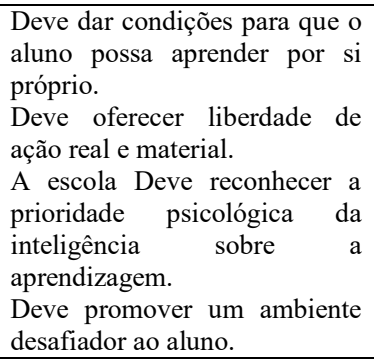 & $\begin{array}{l}\text { Papel essencialmente "ativo" de } \\
\text { observar, experimentar, } \\
\text { comparar, relacionar, analisar, } \\
\text { justapor, compor, encaixar, } \\
\text { levantar hipóteses, argumentar } \\
\text { etc. }\end{array}$ & $\begin{array}{l}\text { PDI } \\
\text { PPI } \\
\text { DCN } \\
\text { PPC }\end{array}$ & $\begin{array}{l}\text { Deve criar situações } \\
\text { desafiadoras e } \\
\text { desequilibradoras, por } \\
\text { meio da orientação. Deve } \\
\text { estabelecer condições de } \\
\text { reciprocidade e e } \\
\text { cooperação ao mesmo } \\
\text { tempo moral e racional. }\end{array}$ & $\begin{array}{l}\text { Deve desenvolver a inteligência, considerando o sujeito inserido } \\
\text { numa situação social. } \\
\text { A inteligência constrói-se a partir da troca do organismo com o } \\
\text { meio, por meio das ações do indivíduo. } \\
\text { Baseados no ensaio e no erro, na pesquisa, na investigação, na } \\
\text { solução de problemas, facilitando o "aprender a pensar". } \\
\text { Ênfase nos trabalhos em equipe e jogos. }\end{array}$ \\
\hline SOCIOCULTURAL & $\begin{array}{l}\text { Deve ser organizada e estar } \\
\text { funcionando bem para } \\
\text { proporcionar os meios para que } \\
\text { a educação se processe em seus } \\
\text { múltiplos aspectos. }\end{array}$ & $\begin{array}{l}\text { Uma pessoa concreta, objetiva, } \\
\text { que determina e é determinada } \\
\text { pelo social, político, econômico, } \\
\text { individual (pela história). } \\
\text { Deve ser capaz de operar } \\
\text { conscientemente mudanças na } \\
\text { realidade. }\end{array}$ & $\begin{array}{l}\text { PDI } \\
\text { PPI } \\
\text { DCN } \\
\text { PPC }\end{array}$ & $\begin{array}{l}\text { É o educador que } \\
\text { direciona e conduz o } \\
\text { processo de ensino e } \\
\text { aprendizagem. A relação } \\
\text { entre professor e aluno } \\
\text { deve ser horizontal. }\end{array}$ & $\begin{array}{l}\text { Os objetivos educacionais são definidos a partir das necessidades } \\
\text { concretas do contexto histórico-social no qual se encontram os } \\
\text { sujeitos. } \\
\text { Busca uma consciência crítica. } \\
\text { O diálogo e os grupos de discussão são fundamentais para o } \\
\text { aprendizado. } \\
\text { Os "temas geradores" para o ensino devem ser extraídos da prática } \\
\text { de vida dos educandos. }\end{array}$ \\
\hline
\end{tabular}

Fonte: Elaborado pelo autor 


\section{A EXPRESSÃO DA LIDERANÇA NA PRÁTICA DOCENTE: UM ESTUDO COM PROFESSORES \\ UNIVERSITÁRIOS DE CURSOS DE ADMINISTRAÇÃO \\ DOI: https://doi.org/10.5007/1983-4535.2021.e73094}

No referido quadro, portanto, estão expressas as dimensões que serviram de base a este trabalho, sistematizando a prática docente como uma conjunção de conceitos, determinantes para a delimitação da prática. A primeira dimensão (Universidade) explicita a compreensão do docente acerca do ambiente em que está inserido profissionalmente. A segunda dimensão (Aluno) diz respeito à percepção do professor quanto ao "lugar" ou significado atribuído ao aluno no processo educativo. A terceira dimensão (Regulação) expressa a intenção de se verificar se o docente percebe que a regulação imposta pelo Estado ao ensino superior tem impactos ou reflexos na sua ação cotidiana. Já a quarta dimensão (Professor) visa verificar como o professor é situado no processo de ensino e a relação professor-aluno e aluno-professor. Por fim, a quinta e última dimensão (Processo educativo), analisa como acontece o processo educativo, ou seja, como é expressa a ação docente por meio das estratégias de ensino escolhidas pelo professor, sua forma predominante de avaliação.

\subsection{LIDERANÇA: PRINCIPAIS TEORIAS E SUAS CARACTERÍSTICAS}

O tema liderança vem sendo estudado e aprimorado de acordo com as necessidades e desafios organizacionais. $\mathrm{O}$ tema em si é considerado uma área de interesse entre cientistas das mais diversas áreas do conhecimento. Liderança não é um conceito de fácil definição, principalmente por ser considerada um processo relacional, que envolve tanto os líderes quando os liderados que, organizados, tendem a buscar objetivos comumente estabelecidos (BRYMAN, 2004).

Compreender a representação do tema liderança exige um conhecimento dos caminhos pelos quais passaram as teorias da administração. Estudos na área do comportamento organizacional apresentam a evolução efetiva das teorias da liderança, de acordo com algumas mudanças presentes em pesquisas relacionadas, predominantemente, à sociologia, filosofia, administração e psicologia. (JACKSON; PARRY, 2010).

Definir liderança significa, de forma abrangente, admitir que liderar é um processo que não se restringe às características ou traços que residem no indivíduo, mas que abrange um evento completo e complexo, composto das interações entre liderados e líderes (NORTHOUSE, 2004). Ainda, de forma análoga, pode-se definir liderança como um processo de influenciar as atividades de um ou mais indivíduos, de maneira que estes somem esforços 


\section{A EXPRESSÃO DA LIDERANÇA NA PRÁTICA DOCENTE: UM ESTUDO COM PROFESSORES \\ UNIVERSITÁRIOS DE CURSOS DE ADMINISTRAÇÃO \\ DOI: https://doi.org/10.5007/1983-4535.2021.e73094}

no estabelecimento e execução de metas, quaisquer que sejam elas, em prol do alcance de objetivos comuns (STOGDILL, 1974).

Contudo, pode-se perceber que a falta de consenso quanto ao verdadeiro significado de liderança (BASS, 2008) não diminui a importância do tema. Correntes diversas relacionam a liderança com a atitude de 'fazer as coisas certas', no sentido de direcionamento de indivíduos na busca do alcance dos resultados estabelecidos (MINTZBERG, 2010).

De maneira geral, a questão da liderança abrange os processos gerais de interação e a busca de um ou mais objetivos comuns, não se tratando especificamente de objetivos empresariais, embora o conceito seja amplamente aceito e utilizado desta maneira. Elementos intangíveis são também utilizados para apresentar o tema de modo teórico, tais como a capacidade de inspirar a confiança e o apoio entre as pessoas envolvidas em uma determinada empreitada (DUBRIN, 2003).

Os estudos sobre liderança se desenvolveram, ao longo do tempo, com base em cinco diferentes abordagens que predominaram em distintos momentos nos estudos organizacionais acerca do tema. De acordo com Stewart (2006), os papéis de líderes e seguidores têm se tornado mais elaborados e refinados, à medida da ampliação de estudos e pesquisas.

Nesse sentido, é preciso salientar que as perspectivas teóricas da liderança se alteram em função da complexidade do mundo e das organizações e da transformação das interações humanas e sociais. Com o passar do tempo o entendimento sobre o tema se torna fluído, dinâmico, difuso, permitindo inclusive a análise sob distintas abordagens ao mesmo tempo.

A primeira abordagem sobre a liderança data dos anos 1940, do século XX, e é voltada principalmente para as características do líder, suas qualidades natas e seus traços de personalidade. Na década de 60 , do mesmo século, a perspectiva do estilo de liderança passa a direcionar suas atenções às características comportamentais deste indivíduo, focado em modo de agir e formas de se comportar em relação ao contexto empresarial/social. Pode-se destacar, principalmente, a dimensão contingencial na análise da liderança, considerando, por exemplo, fatores situacionais e contextuais como arcabouço necessário para compreender o processo de liderança.

É a partir dos anos 1980 que as teorias da liderança carismática e transformacional surgem como novas abordagens de estudo acerca do tema. Tais teorias passam a ver o líder enquanto ser que inspira seus seguidores por meio de ideias, comportamentos e palavras, de forma a incentivá-los a alcançar metas e objetivos propostos. 


\section{A EXPRESSÃO DA LIDERANÇA NA PRÁTICA DOCENTE: UM ESTUDO COM PROFESSORES \\ UNIVERSITÁRIOS DE CURSOS DE ADMINISTRAÇÃO \\ DOI: https://doi.org/10.5007/1983-4535.2021.e73094}

Embora uma história prescrita acerca do tema tenha sido construída em relação à evolução do conceito, acredita-se que o termo "liderança", particularmente na língua inglesa (leadership), seja utilizado há mais de 200 anos. Stogdill (1974), por exemplo, crê que o termo tenha aparecido por volta dos anos 1300 depois de Cristo.

De forma análoga, Fiedler (1967), afirma que a preocupação com a liderança é antiga, de tal forma que, já na obra clássica "A República", de Platão, é possível verificar preocupações iniciais sobre o assunto, principalmente no tocante à educação e ao treinamento dos líderes políticos, assim como de grande parte dos filósofos da época.

Fato importante é que, ao observar cuidadosamente a evolução do tema, as diferentes fases dos estudos sobre liderança não tornam os estudos anteriores obsoletos. As teorias tendem a se sobrepor e, muitas vezes, a complementarem-se (RÉ, 2011). Isso porque se trata de um fenômeno subjetivo e processualístico, de caráter complexo, que se transforma na medida em que também se altera a realidade e os padrões das relações entre os indivíduos nos seus diferentes contextos.

Assim, para sistematizar a evolução dos conceitos e abordagens sobre o tema da liderança, a figura 2 busca sintetizar as principais teorias de liderança, quais sejam: as Teorias Comportamentais; Teoria Contingencial; Teoria Situacional e; as Teorias da Nova Liderança

Figura 2 Teorias da Liderança - características

\begin{tabular}{|c|c|c|c|}
\hline \multicolumn{2}{|c|}{ Abordagens da liderança } & Características & Autores \\
\hline \multirow{3}{*}{$\begin{array}{l}\text { Teoria } \\
\text { comportamental }\end{array}$} & $\begin{array}{c}\text { Autocrático / } \\
\text { Orientado para } \\
\text { produção }\end{array}$ & $\begin{array}{l}\text { O líder é o encarregado por tomar decisões sem } \\
\text { participação dos demais }\end{array}$ & \multirow{3}{*}{$\begin{array}{l}\text { Lippit; } \\
\text { White } \\
(1975)\end{array}$} \\
\hline & $\begin{array}{l}\text { Democrático/ } \\
\text { Orientado para o } \\
\text { empregado }\end{array}$ & $\begin{array}{l}\text { Tende a estimular o grupo a debater para tomar } \\
\text { uma decisão }\end{array}$ & \\
\hline & Laissez-faire & Não interfere deixando a decisão para o grupo & \\
\hline $\begin{array}{l}\text { Teoria } \\
\text { contingencial }\end{array}$ & Liderança contingencial & $\begin{array}{l}\text { O líder é voltado para as tarefas ou relações que } \\
\text { dependem da situação em que o mesmo se } \\
\text { encontra. Admirado pelos seguidores. }\end{array}$ & $\begin{array}{l}\text { Fiedler } \\
(1967)\end{array}$ \\
\hline \multirow{4}{*}{$\begin{array}{c}\text { Teoria } \\
\text { Situacional }\end{array}$} & $\begin{array}{c}\text { Maturidade baixa - } \\
\text { determinar }\end{array}$ & Fornece instruções detalhadas da tarefa & \multirow{4}{*}{$\begin{array}{l}\text { Hersey; } \\
\text { Blanchard } \\
\quad(1969)\end{array}$} \\
\hline & $\begin{array}{l}\text { Maturidade entre baixa } \\
\text { e moderada - persuadir }\end{array}$ & Explica decisões e está aberto à perguntas & \\
\hline & $\begin{array}{l}\text { Maturidade entre } \\
\text { moderada e alta - } \\
\text { compartilhar }\end{array}$ & Discute e troca ideias com o liderado & \\
\hline & $\begin{array}{l}\text { Maturidade alto - } \\
\text { delegar }\end{array}$ & $\begin{array}{c}\text { Repassar a responsabilidade das decisões sem } \\
\text { fiscalizar o liderado }\end{array}$ & \\
\hline Nova Liderança & Carismática & $\begin{array}{l}\text { Visão e articulação; disposto a correr riscos; } \\
\text { perceptivo ao ambiente e as necessidades dos } \\
\text { liderados; apresenta comportamentos não } \\
\text { convencionais }\end{array}$ & $\begin{array}{l}\text { House } \\
(1976)\end{array}$ \\
\hline
\end{tabular}




\section{A EXPRESSÃO DA LIDERANÇA NA PRÁTICA DOCENTE: UM ESTUDO COM PROFESSORES \\ UNIVERSITÁRIOS DE CURSOS DE ADMINISTRAÇÃO \\ DOI: https://doi.org/10.5007/1983-4535.2021.e73094}

\begin{tabular}{|c|c|c|c|}
\hline \multicolumn{2}{|c|}{ Abordagens da liderança } & Características & Autores \\
\hline & Transformacional & $\begin{array}{c}\text { Carismático; inspirador; promove a inteligência; } \\
\text { Dá atenção personalizada para cada indivíduo }\end{array}$ & $\begin{array}{c}\text { Bass } \\
(2008)\end{array}$ \\
\cline { 2 - 4 } & Distribuída & $\begin{array}{c}\text { Colabora espontaneamente para execução das } \\
\text { tarefas; compartilha papéis no espaço; participa } \\
\text { de práticas institucionalizadas }\end{array}$ & $\begin{array}{c}\text { Grönn } \\
(2002)\end{array}$ \\
\hline
\end{tabular}

Fonte: elaborada pelo autor (2018).

\section{PROCEDIMENTOS METODOLÓGICOS}

Considerando a problemática identificada, a pesquisa foi orientada sob a abordagem qualitativa. De acordo com Bryman (2004), a pesquisa qualitativa tende a focar nos indivíduos e suas interações, permitindo que o processo metodológico ocorra de modo flexível e que os resultados alcançados reflitam o que os participantes consideram efetivamente relevante no fenômeno estudado. A pesquisa de abordagem qualitativa, especificamente em liderança, possibilita enxergar tal fenômeno por dois vieses (de líderes e de liderados), o que de fato pode permitir uma condição de visualização do tema, de forma a abranger o maior número de significados sobre o tema estudado. Neste estudo, especificamente buscou-se verificar a liderança expressa pelos professores de cursos superiores na área de administração, considerando que estes possam ser líderes.

Com relação ao delineamento de pesquisa, foi escolhido o estudo de caso, uma vez que pretendeu-se aprofundar o conhecimento acerca do fenômeno estudado - a liderança - em um dado contexto: o contexto da prática docente de professores universitários de uma determinada área, neste caso especifico, os sujeito da pesquisa foram professores de disciplinas centro de cursos superiores de administração de Universidades estabelecidas na mesorregião da Grande Florianópolis, no Estado de Santa Catarina (FECAM, 2017). A escolha por Universidades, enquanto foco do estudo, ocorreu exclusivamente pela presença das atividades consideradas pilares da educação superior, quais sejam: 1) ensino, 2) pesquisa e; 3) extensão; exigências do Ministério da Educação para que a IES seja efetivamente nomeada Universidade (MEC, 2006).

Ao todo, na mesorregião estão estabelecidas um total de quatro Universidades, sendo que nestas são ofertados cursos superiores em Administração também delimitados como cenário desta pesquisa, dada a temática pesquisada. É importante ressaltar, contudo, que não foram consideradas as Universidades que possuem apenas polos de Educação à distância na região, uma vez que se busca estabelecer ligação entre a liderança expressa na prática docente, ou seja no ambiente de sala de aula presencial. 


\section{A EXPRESSÃO DA LIDERANÇA NA PRÁTICA DOCENTE: UM ESTUDO COM PROFESSORES \\ UNIVERSITÁRIOS DE CURSOS DE ADMINISTRAÇÃO \\ DOI: https://doi.org/10.5007/1983-4535.2021.e73094}

Com relação à escolha dos professores participantes, ou seleção da amostra, a mesma ocorreu, em um primeiro momento, de forma aleatória, considerando sua atuação em áreas/disciplinas profissionalizantes dos cursos. Em um segundo momento, os professores participantes da pesquisa foram identificados e definidos por conveniência, dada a sua disponibilidade em participar da pesquisa (YIN, 2016). Assim, foram entrevistados, quatorze (14) docentes, os quais atuam no ensino superior de Administração há, pelo menos, cinco (5) anos, em disciplinas base do currículo do curso. A formação em nível de graduação dos entrevistados é diversificada: Administração, Contabilidade, Engenharia e Psicologia. Entretanto, é importante ressaltar que todos possuem cursos de Pós-graduação (lato e stricto sensu); dos quatorze (14) entrevistados, somente quatro (4) ainda não possuem o Doutorado.

Os dados da pesquisa foram coletados a partir da realização de entrevistas com roteiro semiestruturado, a escolha se deve à possibilidade de que os participantes sejam escolhidos por suas experiências que tendem a refletir o fenômeno estudado (COOPER; SCHINDLER, 2016), além da possibilidade de explorar motivações e dilemas de posicionamento dos envolvidos, bem como permite que os entrevistados discorram livremente sobre o tema em questão (MINAYO, 2009).

Para que fosse possível identificar a percepção de prática docente dos professores e relacionar com as concepções de liderança expressas pelos sujeitos da pesquisa, buscou-se identificar a prática docente tendo como base o modelo de Mizukami (1986), dividindo a prática docente em cinco dimensões que buscam identificar a visão do docente. A primeira dimensão [UNIVERSIDADE] corresponde à visão do entrevistado acerca do modelo de universidade adotado no Brasil, e foi trabalhada na entrevista por meio de três (3) questões abertas. Para tratar da segunda dimensão, [ALUNO], foram apresentadas duas (2) questões abertas, com a intenção de identificar a percepção do entrevistado acerca do papel do aluno no contexto relacionado ao processo educativo. Já quanto à terceira dimensão para se conhecer a prática docente, [REGULAÇÃO], foram apresentadas na entrevista duas (2) perguntas abertas, visando verificar, segundo a descrição da ação docente, a relação que ele faz com sua prática e as regulações impostas ao ensino superior brasileiro. A quarta dimensão, [PROFESSOR], abrange duas (2) questões abertas, visando conhecer a percepção do entrevistado relacionada ao modo como o docente deve ser percebido em sala de aula e seu papel no processo educativo. Por fim, a quinta dimensão, [PROCESSO EDUCATIVO], composta de duas (2) perguntas abertas, tem a intenção de verificar a opinião do professor 


\section{A EXPRESSÃO DA LIDERANÇA NA PRÁTICA DOCENTE: UM ESTUDO COM PROFESSORES \\ UNIVERSITÁRIOS DE CURSOS DE ADMINISTRAÇÃO \\ DOI: https://doi.org/10.5007/1983-4535.2021.e73094}

relacionada a como este percebe a receptividade de seus alunos às suas escolhas para o processo educativo.

De forma a sistematizar os relatos obtidos nas entrevistas, buscou-se gravá-las e, posteriormente, transcrevê-las integralmente em processador de textos (Microsoft Word $\left.{ }^{\circledR}\right)$. É preciso, contudo, ressaltar que a gravação das entrevistas fora comunicada previamente aos participantes, bem como a informação de que seria preservada a identificação da instituição de ensino e dos entrevistados, caracterizados por Professor 01, Professor 02, seguindo esta sequência, com o intuito de resguardar a identidade dos sujeitos entrevistados, fator predominante para o aceite dos docentes em participar. A análise dos dados ocorreu a partir da descrição e interpretação dos conteúdos das entrevistas semiestruturadas realizadas com os professores, partindo das categorias de análise pré-estabelecidas, quais sejam, prática docente (figura 1) e liderança (figura 2). O processo da interpretação dos dados consiste em extrair sentido dos dados, envolvendo uma reflexão contínua sobre eles. (CRESWELL, 2010).

\section{RESULTADOS}

Buscou-se, conhecer a prática docente dos professores de cursos de Administração com base nas dimensões Universidade, Professor, Aluno e Processo Educativo (MIZUKAMI, 1986) e respectivos elementos descritos na figura 1. Entende-se que a caracterização da prática docente dos professores pesquisados pode, preliminarmente, ser alinhada às abordagens de educação (concepções educacionais) para, no segundo momento, ser associada às expressões da liderança, foco da pesquisa e evidenciadas no cerne dessa prática.

Nesse contexto, buscou-se, na figura 3, reunir todas as evidências encontradas sobre a percepção da prática docente e suas dimensões nos relatos de cada professor pesquisado, integralizando os dados e relacionando-os às abordagens educacionais que orientam, ainda que de forma subliminar, as suas atividades em sala de aula.

Ao observar a relação entre as percepções sobre a prática docente e as abordagens da educação explicitadas por cada professor, é possível identificar que, quando observada somente a primeira dimensão - a Universidade - os professores estão alinhados, predominantemente, à abordagem tradicional da educação. Tal constatação revela, portanto, que em sua maioria os docentes acreditam que a universidade seja o lugar ideal para a realização da educação, uma vez que esta ainda tem a importante função de preparar os indivíduos para a sociedade (MIZUKAMI, 1986). Já quanto à segunda dimensão, o Aluno, os 
professores se enquadram predominantemente na abordagem cognitivista da educação, considerando que o acadêmico precisa ter um papel essencialmente ativo de observar, experimentar, comparar, relacionar, analisar, justapor, compor, encaixar, levantar as hipóteses, argumentar, etc., acerca dos conhecimentos obtidos na educação superior e superar as barreiras da sala de aula (MIZUKAMI, 1986).

Figura 3 A relação entre a prática docente e as abordagens da educação orientadoras dos professores pesquisados

\begin{tabular}{|c|c|c|c|c|}
\hline $\begin{array}{l}\text { PRÁTICA } \\
\text { DOCENTE } \\
\text { ABORDAGENS }\end{array}$ & $\begin{array}{c}\text { DIMENSÃO } \\
\text { UNIVERSIDADE }\end{array}$ & $\begin{array}{l}\text { DIMENSÃO } \\
\text { ALUNO }\end{array}$ & $\begin{array}{c}\text { DIMENSÃO } \\
\text { PROFESSOR }\end{array}$ & $\begin{array}{r}\text { DIMENSÃO } \\
\text { PROCESSO } \\
\text { EDUCATIVO }\end{array}$ \\
\hline Tradicional & $\begin{array}{c}\text { Professor } 1 \\
\text { Professor } 5 \\
\text { Professor } 6 \\
\text { Professor } 7 \\
\text { Professor } 10 \\
\text { Professor } 13\end{array}$ & - & $\begin{array}{l}\text { Professor } 2 \\
\text { Professor } 3 \\
\text { Professor } 8\end{array}$ & $\begin{array}{c}\text { Professor } 1 \\
\text { Professo } 2 \\
\text { Professor } 3 \\
\text { Professor } 5 \\
\text { Professor } 6 \\
\text { Professor } 7 \\
\text { Professor } 10 \\
\text { Professor } 13 \\
\text { Professor } 14 \\
\end{array}$ \\
\hline Comportamentalista & $\begin{array}{l}\text { Professor } 9 \\
\text { Professo } 11\end{array}$ & - & $\begin{array}{c}\text { Professor } 9 \\
\text { Professor } 10 \\
\text { Professor } 11 \\
\text { Professor } 12 \\
\end{array}$ & 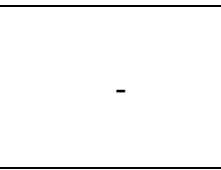 \\
\hline Humanista & Professor 3 & $\begin{array}{l}\text { Professor } 1 \\
\text { Professor } 3 \\
\text { Professor } 5 \\
\text { Professor } 10\end{array}$ & $\begin{array}{c}\text { Professor } 4 \\
\text { Professor } 5 \\
\text { Professor } 6 \\
\text { Professor } 7 \\
\text { Professor } 13 \\
\text { Professor } 14 \\
\end{array}$ & - \\
\hline Cognitivista & $\begin{array}{l}\text { Professor } 2 \\
\text { Professor } 8 \\
\text { Professor } 12 \\
\text { Professor } 14\end{array}$ & $\begin{array}{c}\text { Professor } 2 \\
\text { Professor } 4 \\
\text { Professor } 6 \\
\text { Professor } 7 \\
\text { Professor } 8 \\
\text { Professor } 9 \\
\text { Professor } 11 \\
\text { Professor } 13 \\
\text { Professor } 14 \\
\end{array}$ & $\begin{array}{l}\text { Professor } 9 \\
\text { Professor } 10 \\
\text { Professor } 11\end{array}$ & $\begin{array}{l}\text { Professor } 1 \\
\text { Professor } 4 \\
\text { Professor } 7 \\
\text { Professor } 8 \\
\text { Professor } 9 \\
\text { Professor } 11 \\
\text { Professor } 12 \\
\text { Professor } 14\end{array}$ \\
\hline Sociocultural & Professor 4 & Professor 12 & Professor 1 & - \\
\hline
\end{tabular}

Fonte: dados da pesquisa.

No mesmo sentido, quando observada a terceira dimensão da prática docente, a Regulação, pode-se aferir que os docentes, em sua maioria, compreendem a necessidade da regulação do ensino superior brasileiro e sentem positivamente os impactos da regulação em sua prática docente, enquanto balizadora da formação do perfil do egresso do curso em questão. 


\section{A EXPRESSÃO DA LIDERANÇA NA PRÁTICA DOCENTE: UM ESTUDO COM PROFESSORES \\ UNIVERSITÁRIOS DE CURSOS DE ADMINISTRAÇÃO \\ DOI: https://doi.org/10.5007/1983-4535.2021.e73094}

Ao observar a quarta dimensão da prática docente, a dimensão Professor, por sua vez, pode-se aferir que a maioria dos professores pensa que seu papel seja o de facilitador do conhecimento, característica da concepção humanista de educação. Com relação as evidências expressas da prática docente em sua quinta dimensão, o Processo Educativo, por fim, verificase novamente a predominância de uma atuação orientada por bases tradicionais de educação, justificada na escolha de estratégias de ensino como aula expositivo-dialogada e avaliações em formato de provas de conhecimento específicos. A diversidade constatada nas referências que orientam as percepções das práticas docentes dos sujeitos da pesquisa, em específico no que foi revelado nas cinco dimensões consideradas para análise destas práticas, demonstra a complexidade que é "rotular" ou adequar a atuação do professor em uma única concepção educacional. Os dados revelam uma multidimensionalidade associada à visão que o professor adota na sua prática docente, podendo-se afirmar, com base nos dados, que o mesmo tem sua atuação orientada por múltiplas abordagens.

Nesta perspectiva, as expressões da prática docente dos professores, sujeitos da pesquisa, puderam ser entendidas a partir de cada uma das dimensões analisadas, tomando como base a obra de Mizukami (1986), revelando individualidades que, certamente, são expressas no seu dia a dia da sala de aula. A prática docente, portanto, se mostrou individualizada nas percepções e ações descritas pelos professores pesquisados, que revelam valores e crenças alinhados à como percebem o mundo em que atuam como tal; deste modo, podem ser entendidos como indivíduos complexos, revelando práticas docentes diversas, mas sob paradigmas educacionais que se interpõem ou complementam. A figura 4 tem a intenção de relacionar a expressão da prática docente e a expressão de liderança de cada professor pesquisado.

Uma vez que se explicitou as abordagens da educação predominantes no grupo de professores pesquisados, por meio da análise da categoria elencada neste trabalho como "prática docente" e suas cinco dimensões, neste momento serão apontadas as posturas de cada docente, relacionando sua prática com características expressivas de liderança, utilizando como base as concepções sintetizadas na figura 2 (FIEDLER, 1967; HERSEY; BLANCHARD, 1969 LIPPIT;WHITE, 1975; HOUSE, 1976; GRÖNN 2002; BASS, 2008) . Esse procedimento analítico tem o propósito de responder ao objetivo da presente pesquisa, que buscou verificar a relação entre a prática docente de professores de cursos superiores na área de Administração e as concepções de liderança expressas no contexto da sala de aula. 


\section{A EXPRESSÃO DA LIDERANÇA NA PRÁTICA DOCENTE: UM ESTUDO COM PROFESSORES \\ UNIVERSITÁRIOS DE CURSOS DE ADMINISTRAÇÃO \\ DOI: https://doi.org/10.5007/1983-4535.2021.e73094}

Figura 4 Concepções de liderança expressas na prática docente dos professores pesquisados

\begin{tabular}{|c|c|c|c|c|c|}
\hline & $\begin{array}{c}\text { EXPRESSÃO DA } \\
\text { PRÁTICA DOCENTE }\end{array}$ & $\begin{array}{l}\text { EXPRESSÃO DE } \\
\text { LIDERANÇA }\end{array}$ & & $\begin{array}{c}\text { EXPRESSÃO DA } \\
\text { PRÁTICA DOCENTE }\end{array}$ & $\begin{array}{c}\text { EXPRESSÃO } \\
\text { DE } \\
\text { LIDERANÇA }\end{array}$ \\
\hline Professor 1 & $\begin{array}{l}\text { Estimula o diálogo; } \\
\text { compartilha papéis Instrui, } \\
\text { explica, discute e } \\
\text { responsabiliza; }\end{array}$ & $\begin{array}{l}\text { Democrático } \\
\text { Situacional } \\
\text { Carismático. } \\
\end{array}$ & Professor 8 & $\begin{array}{l}\text { Promove a inteligência; } \\
\text { autoridade; } \\
\text { colabora para a execução } \\
\text { das tarefas; }\end{array}$ & $\begin{array}{c}\text { Autocrático } \\
\text { Transformacional } \\
\text { Distribuída }\end{array}$ \\
\hline Professor 2 & $\begin{array}{c}\text { Encarregado pela } \\
\text { "transmissão" do } \\
\text { conhecimento; autoritário; } \\
\text { explica e está aberto à } \\
\text { perguntas }\end{array}$ & $\begin{array}{l}\text { Autocrático } \\
\text { Situacional }\end{array}$ & Professor 9 & $\begin{array}{c}\text { Promove a inteligência; } \\
\text { colabora para a execução } \\
\text { das tarefas; }\end{array}$ & $\begin{array}{l}\text { Transformacional } \\
\text { Distribuída }\end{array}$ \\
\hline Professor 3 & $\begin{array}{c}\text { Encarregado pela } \\
\text { "transmissão" do } \\
\text { conhecimento; autoritário; } \\
\text { Instrui, explica, discute e } \\
\text { responsabiliza; }\end{array}$ & $\begin{array}{l}\text { Autocrático } \\
\text { Situacional } \\
\text { Distribuída }\end{array}$ & Professor 10 & $\begin{array}{l}\text { Encarregado pela } \\
\text { "transmissão" do } \\
\text { conhecimento; colabora } \\
\text { para a execução das } \\
\text { tarefas; }\end{array}$ & $\begin{array}{l}\text { Democrático } \\
\text { Distribuída }\end{array}$ \\
\hline Professor 4 & $\begin{array}{c}\text { Promove a inteligência; } \\
\text { colabora para a execução } \\
\text { das tarefas; }\end{array}$ & $\begin{array}{l}\text { Transformacional } \\
\text { Distribuída }\end{array}$ & Professor 11 & $\begin{array}{c}\text { Promove a inteligência; } \\
\text { colabora para a execução } \\
\text { das tarefas; }\end{array}$ & $\begin{array}{l}\text { Transformacional } \\
\text { Distribuída }\end{array}$ \\
\hline Professor 5 & $\begin{array}{c}\text { Encarregado pela } \\
\text { "transmissão" do } \\
\text { conhecimento; colabora } \\
\text { para a execução das } \\
\text { tarefas; }\end{array}$ & $\begin{array}{l}\text { Democrático } \\
\text { Distribuída }\end{array}$ & Professor 12 & $\begin{array}{c}\text { Promove a inteligência; } \\
\text { colabora para a execução } \\
\text { das tarefas; }\end{array}$ & $\begin{array}{l}\text { Transformacional } \\
\text { Distribuída }\end{array}$ \\
\hline Professor 6 & $\begin{array}{c}\text { Encarregado pela } \\
\text { "transmissão" do } \\
\text { conhecimento; colabora } \\
\text { para a execução das } \\
\text { tarefas; }\end{array}$ & $\begin{array}{l}\text { Democrático } \\
\text { Distribuída }\end{array}$ & Professor 13 & $\begin{array}{c}\text { Encarregado pela } \\
\text { "transmissão" do } \\
\text { conhecimento; colabora } \\
\text { para a execução das } \\
\text { tarefas; }\end{array}$ & $\begin{array}{l}\text { Democrático } \\
\text { Distribuída }\end{array}$ \\
\hline Professor 7 & $\begin{array}{c}\text { Encarregado pela } \\
\text { "transmissão" do } \\
\text { conhecimento; colabora } \\
\text { para a execução das } \\
\text { tarefas; }\end{array}$ & $\begin{array}{l}\text { Democrático } \\
\text { Distribuída }\end{array}$ & Professor 14 & $\begin{array}{c}\text { Promove a inteligência; } \\
\text { colabora para a execução } \\
\text { das tarefas; }\end{array}$ & $\begin{array}{l}\text { Transformacional } \\
\text { Distribuída }\end{array}$ \\
\hline
\end{tabular}

Fonte: dados primários.

Observando os dados analisados é possível, a partir da descrição das atividades e das percepções dos professores acerca da prática docente e suas dimensões, verificar características da liderança subjacentes à sua atuação em sala de aula, revelando perfís e processos associados da liderança à prática docente.

Quando aproximadas as duas categorias de análise utilizadas como base para o alcance dos objetivos desta pesquisa, pode-se em dada medida observar aspectos complementares. Tanto as abordagens da educação utilizadas para a construção do que neste trabalho se chamou de "prática docente", bem como as teorias da liderança, estão sujeitas a evoluções e diferentes interpretações.

Foi possível identificar que os docentes entrevistados, quando do cruzamento das categorias, de fato observar, que os professores apresentam comportamentos característicos de líderes que podem ser elencados em diversas das abordagens de liderança, demonstrando que a liderança expressa na prática docente tende a se manifestar de formas diferentes em cada 


\section{A EXPRESSÃO DA LIDERANÇA NA PRÁTICA DOCENTE: UM ESTUDO COM PROFESSORES \\ UNIVERSITÁRIOS DE CURSOS DE ADMINISTRAÇÃO \\ DOI: https://doi.org/10.5007/1983-4535.2021.e73094}

uma das disciplinas ministradas pelo docente, e mesmo na Universidade em que atua, na medida em que a prática tende a ser institucionalizada.

Tais fatos associados, determinam que a prática docente seja sustentada nas abordagens da educação, regulações específicas do ensino superior, nas ferramentas de ensino-aprendizagem escolhidas pelo professor e na maneira como este se percebe no contexto de sala de aula, permitindo que se faça uma análise multifacetada de seus comportamentos e concepções frente à complexa atividade que se pretende categorizar. Ou seja, analisar os posicionamentos de cada um dos docentes, frente às cinco dimensões componentes da prática. Isso permitiu que se delimitasse, de certa maneira, a forma como o entrevistado vê o mundo a sua volta; como pensa que seu aluno deve se posicionar frente à possibilidade de uma formação profissional; como ele, enquanto indivíduo, se relaciona com seus alunos dentro de uma estrutura organizada; elementos fundamentais para que ele faça escolhas de como conduzir o processo educativo em que está envolvido.

É desta maneira que o professor é comumente desafiado, sua interação com o meio (universidade, alunos, etc.) é delimitada tão somente pela sua capacidade de "fazer as coisas certas", de direcionar seus alunos na busca de seus objetivos, atuando como líderes, na medida em que lideram os processos de ensino para dentro e além da sala de aula, na constante construção do perfil profissional de seu aluno.

Contudo, ao serem observadas as dimensões da prática docente, quais sejam, a Universidade, o Aluno, a Regulação, o Professor e os Processos Educativos, a liderança se explicita de forma observável somente nas duas últimas dimensões: o professor e o processo educativo, uma vez que estas são efetivamente onde abstração de sua visão de mundo tende a se explicitar. Ou seja, por meio de como este se percebe frente ao seu aluno e escolhe as ferramentas para encaminhá-lo ao seu real objetivo.

Quer o docente se perceba como uma figura digna de respeito ou admiração, quer se compreenda como facilitador do processo de ensino, ou mesmo como alguém que precisa criar situações desafiadoras para seus alunos, a operacionalização de suas concepções educacionais, convertidas nas suas escolhas, é que demonstrarão para o seu aluno uma ou outra expressão de liderança. E isso somente acontecerá ao longo do semestre letivo, uma vez que a liderança em si pode ser considerada um processo relacional, capaz de envolver líderes e liderados em busca de objetivos comumente estabelecidos (BRYMAN, 2004) 


\section{CONSIDERAÇÕES FINAIS}

O propósito deste artigo foi abordar a temática da liderança visando aferir suas expressões na prática docente de professores de cursos superiores de Administração da mesorregião da Grande Florianópolis. Partiu-se do entendimento de que a liderança pode ser considerada um processo relacional, envolvendo líderes e liderados que possuem um propósito comumente estabelecido. Sendo assim, o objetivo desta pesquisa foi verificar a relação entre a percepção da prática docente de professores de cursos superiores na área de Administração e as concepções de liderança expressas no contexto do ambiente de sala de aula.

O contexto do estudo foram professores de cursos superiores de Administração sediados nas quatro Universidades da Mesorregião da Grande Florianópolis, no Estado de Santa Catarina. A escolha pelas instituições se deu de acordo com a classificação do Ministério da Educação Brasileiro, que classifica por Universidade uma instituição de ensino superior que atue com ensino, pesquisa e extensão.

Como resultados da pesquisa, foi possível descrever as percepções da prática docente dos professores a partir das concepções educacionais, aspectos regulatórios e processos educativos que orientam sua atuação e, por meio dela, identificar a expressão das concepções de liderança no contexto das práticas docentes dos professores e relacioná-las.

Para o alcance dos objetivos propostos foram apresentados os fundamentos teóricoempíricos em torno das temáticas principais da pesquisa e seus desdobramentos conceituais. Inicialmente, buscou-se estabelecer a categoria intitulada "prática docente". Quando observadas as abordagens da educação apresentadas por Mizukami (1986), em seu livro "Ensino: as abordagens do processo", pode-se estabelecer 05 (cinco) categorias que delimitam a maneira com que os professores se posicionam: a maneira como o docente percebe o ambiente universitário, o seu aluno, os impactos da regulação no seu dia a dia, e como faz suas escolhas relacionadas as estratégias de ensino-aprendizagem.

Da mesma maneira, quando observadas as perspectivas teóricas da liderança e suas abordagens, buscou-se privilegiar os conceitos clássicos de liderança, bem como as teorias da nova abordagem da liderança, contemplando as teorias da liderança carismática, transformacional e distribuída.

Em relação à delimitação da percepção da prática docente dos professores pesquisados, constatou-se por meio das entrevistas que os mesmos possuem visões distintas 


\section{A EXPRESSÃO DA LIDERANÇA NA PRÁTICA DOCENTE: UM ESTUDO COM PROFESSORES \\ UNIVERSITÁRIOS DE CURSOS DE ADMINISTRAÇÃO \\ DOI: https://doi.org/10.5007/1983-4535.2021.e73094}

relacionadas às dimensões da prática docente. Desta forma, constatou-se que não é possível filiar um professor a uma determinada abordagem da educação. Tal achado evidencia a possibilidade de que um professor tenha visões distintas, porém complementares acerca das dimensões da prática docente.

Quando questionados sobre a primeira dimensão da prática docente, a Universidade, os professores se enquadram predominantemente na abordagem tradicional da educação, deixando transparecer que a maioria ainda acredita que a Universidade seja o local ideal para a realização da educação. Quando questionados com relação a como desejam que seus alunos se posicionem frente ao processo de ensino, a resposta predominante foi de que os acadêmicos precisam apresentar um papel ativo, predominando como sujeitos de sua educação. Já com relação aos impactos da legislação do ensino superior na atividade prática, a maioria dos professores acredita que as regulações impostas tendem a impactar positivamente nas suas aulas.

No mesmo sentido, quando questionados sobre a dimensão professor, em sua maioria os docentes acreditam que seu papel é o de transmissor dos conteúdos aos alunos e, por consequência, de autoridade em sala de aula. E, quando questionados com relação à quinta dimensão da prática docente, o processo educativo, a maioria dos professores afirmou escolher como estratégia de ensino-aprendizagem a aula expositiva e dialogada.

Por fim, por meio das respostas e o delineamento das expressões da prática docente de cada professor, foi possível identificar expressões de liderança de maneira individual. Ao verificar as relações de maneira agregada, pode-se concluir que não é possível associar a prática docente exclusivamente a uma única abordagem de liderança, uma vez que indivíduos geralmente são multifacetados e tendem a apresentar comportamentos, complexos, por vezes difusos e paradoxais. Nesse sentido, as evidências demonstraram que os professores de cursos superiores na área de Administração de Universidades da Mesorregião da Grande Florianópolis, apresentam expressões de liderança expressas na prática docente. Tais expressões são múltiplas e expressas, principalmente, pela forma que este professor constrói sua atuação profissional, ficando explícitas, predominantemente, na maneira como ele se coloca frente ao processo educativo, por meio da escolha de suas estratégias de ensinoaprendizagem e da maneira como vê seu papel, seja ele de transmissor dos conteúdos ou de facilitador do processo de aprendizagem. 
Os resultados da pesquisa, levaram o pesquisador a concluir que, apesar dos entrevistados apresentarem-se como líderes em suas salas de aula, suas expressões de liderança são, por vezes, não transpassadas aos alunos, por conta de sua postura frente a realidade educacional encontrada. Como docente, atuante em cursos superiores em Administração em uma das universidades da região abordada, o pesquisador também pode concluir identificar quais são as características de liderança expressas em sua prática docente. Tal dificuldade se deve, muitas vezes, pela impossibilidade de escolher estratégias de ensinoaprendizagem mais condizentes com a realidade imposta pela instituição, aspecto que foi ponto de concordância de alguns professores abordados no estudo.

Por fim, ao encerrar o presente estudo, pode-se afirmar que esta pesquisa é uma contribuição aos estudos da liderança, especialmente de sua relação com as abordagens da educação e suas práticas docentes. Nesse sentido, novas possibilidades de pesquisa podem ser pensadas, como a análise da liderança docente sob a abordagem da liderança complexa, considerando a multidimensionalidade percebida nas conclusões da análise; bem como a busca pela identificação das expressões da liderança na prática docente a partir das percepções dos estudantes.

\section{REFERÊNCIAS}

AQUINO, O. F.; PUENTES, R. V. Trabalho Didático na Univerdade: estratégias de formação. Campinas: Alinea, 2011. 145 p.

ARANHA, M.L.A. História da Educação. 2.ed. São Paulo: Moderna, 2000

BASS, B.M. The Bass handbook of leadership: theory, research \& managerial applications. 4 ed. rev. and up. New York: Free Press, 2008.

BRYMAN, A. Liderança na organização. In: CLEGG, S. R.; HARDY; C.; NORD, W. R. Handbook de estudos organizacionais, v. 3. São Paulo: Atlas, 2004.

BÜHLER, C. Bons Professores que fazem a diferença na vida do aluno: saberes e práticas que caracterizam sua liderança. 2010. 169 f. Tese (Doutorado) - Curso de Doutorado em Educação, Faculdade e Educação, Pontifícia Universidade Católica do Rio Grande do Sul, Porto Alegre, 2010.

CASASSUS, J. O clima emocional é essencial para haver aprendizagem. Revista Nova Escola, ano XXIII, n. 218, dez. 2008

COOPER, D. R.; SCHINDLER, Pamela S.. Métodos de pesquisa em administração. 12. ed. Porto Alegre: AMGH, 2016. 695 p. 
CRESWELL, J. W. Projeto de pesquisa: métodos qualitativo, quantitativo e misto. 3. ed. Porto Alegre: Artmed Editora, 2010. 296 p. Tradução de: Magda Lopes.

DANIELSON, C. Teacher Leadership: that Strengthens Professional Practice. Alexandria: Ascd, 2006.

D'ANTOlA, A. (Org.). A Prática Docente na Universidade. São Paulo: Epu, 1992. 104 p.

DUBRIN, A. J. Fundamentos do comportamento organizacional. São Paulo: Thomson, 2003.

FECAM; MUNICÍPIOS, Federação Catarinense de. Banco de Indicadores: Mesorregiões de Santa Catarina. 2017. Disponível em:

$<$ http://indicadores.fecam.org.br/indice/estadual/ano/2017>. Acesso em: 08 jul. 2017.

FREIRE, P. Pedagogia da autonomia: saberes necessários à prática educativa. 39. ed. São Paulo: Paz e Terra, 1992.

FIEDLER, F. A theory of leadership effectiveness. New York: McGraw-Hill Book Company, 1967.

GRONN, P. Distributed Leadership. In: LEITHWOOD, K.; HALLINGER, P. (eds) Second International Handbook of Educational Leadership and Administration. Dordrecht: Kluwer, 2002, p. 653-696.

HERSEY, P.; BLANCHARD, K. H. Life cycle theory of leadership. Training \& development journal, v. 23, n. 5, p. 26, 1969.

HOUSE, R. J. A Theory of Charismatic Leadership: Working Paper Series. In: SOUTHERN ILLINOIS UNIVERSITY FOURTH BIENNIAL LEADERSHIP SYMPOSIUM, 4., 1976, Carbondale. Illinois. Toronto: Toronto University, 1976. p. 4 - 38.

JACKSON, B.; PARRY, K. Um Livro bom, Pequeno e Acessível sobre Liderança. Tradução: Raul Rubenich. Porto Alegre: Bookman, 2010.

KOLB, A. Y.; KOLB, D. A. The learning way: meta-cognitive aspects of experiential learning. Simulation \& Gaming: an Interdisciplinary Journal, v. 40, p. 297-327, 2009.

MINAYO, M.C.S. O desafio do Conhecimento. Pesquisa qualitativa em saúde. 7 ed. São Paulo/Rio de Janeiro: Hucitec/Abrasco, 2009.

MINISTÉRIO DA EDUCAÇÃO (MEC). (2006). Decreto nº 5.773/06, de 09 de maio de 2006. Decreto No 5.773, de 9 de Maio de 2006. BRASIL, DF: Brasil, 09 maio 2006.

Disponível em: <http://www2.mec.gov.br/sapiens/portarias/dec5773.htm>. Acesso em: 30 jul. 2017.

MINTZBERG, H..Managing: Desvendando o dia a dia da gestão. Tradução de Francisco 
Araújo da Costa. Porto Alegre: Bookman, 2010.

MIZUKAMI, M. G. N.. Ensino: as abordagens do processo. São Paulo: Epu, 1986.

NORTHOUSE, P. G. Leadership: theory and practice. 3ed. Thousand Oaks; London; New Dehli: Sage Publications, 2004.

NÚÑES, J. A S. El desarrollo professional del docente universitario. Revista Universidad, México, n.22, p.1-16, jul./dez. 2001.

PÉREZ GÓMEZ, A. A função e formação do professor (a) no ensino para compreensão: diferentes perspectivas. In: GIMÉNO SCRISTÁN, J: PÉREZ GÓMEZ,A . I. Compreender e transformar o ensino. 4.ED. Porto Alegre: Artmed, 1998.

PIMENTA, S. G.; ANASTASIOU, L. G. C. Docência no Ensino Superior. 5. ed. São Paulo: Cortez, 2014.

PLUTARCO, F. F., GRANDVOHL, R. F. Competências dos professores de administração: a visão dos alunos de cursos de graduação. Anais do Encontro da Associação Nacional de PósGraduação e Pesquisa em Administração, Rio de Janeiro, RJ, Brasil, 34. Set. 2010.

RÉ, C. A. T. O Fenômeno da Liderança em escolas públicas de Ensino Médio do Rio Grande do Sul. 2011. 218 f. Tese (Doutorado) - Curso de Programa de Pós-graduação em Engenharia de Produção, Universidade Federal de Santa Catarina, Florianópolis, 2011.

SANTOS, R. V. Abordagens do processo de ensino e aprendizagem. Integração, São Paulo, n. 40, p.19-31, maio 2005. Trimestral.

STEWART, J. Transformational leadership: an envolving concept examined through de works of Burns, Bass, Avolio and Leithwood. Canadian Journal of Educational Administration and Policy. Issue 54, jun 2006.

STOGDILL, R. M. Handbook of leadership: a survey of literature. New York: Free Press, 1974.

TARDIF, M. Saberes docentes e formação de professores. Tradução Francisco Pereira. Petrópolis: Vozes, 2002.p.325

THOONEN, E. E. J. et al. How to improve teaching practices the role of teacher motivation, organizational factors, and leadership practices. Educational Administration Quarterly, v. 47, n. 3, p. 496-536, 2011.

WHITE, R. LIPITT, R. Comportamento do líder e reação dos membros em três climas sociais. In: CARTWRIGT, D.; ZANDER, A. (orgs). Dinâmica de grupo: pesquisa e teoria. São Paulo: EPU, 1975, v. 2.

YIN, Robert K. Pesquisa qualitativa do início ao fim. Porto Alegre: Penso, 2016. 313 p. 